\title{
Benchmarking the Stability of Oxygen Evolution Reaction Catalysts: The Importance of Monitoring Mass Losses
}

\author{
Rasmus Frydendal, ${ }^{[a]}$ Elisa A. Paoli, ${ }^{[a]}$ Brian P. Knudsen, ${ }^{[a]}$ Björn Wickman, ${ }^{[a, b]}$ Paolo Malacrida, ${ }^{[a]}$ \\ Ifan E. L. Stephens, ${ }^{*[a]}$ and Ib Chorkendorff*[a]
}

Because of the rising need for energy storage, potentially facilitated by electrolyzers, improvements to the catalysis of the oxygen evolution reaction (OER) become increasingly relevant. Standardized protocols have been developed for determining critical figures of merit, such as the electrochemical surface area, mass activity and specific activity. Even so, when new and more active catalysts are reported, the catalyst stability tends to play a minor role. In this work, we monitor corrosion on $\mathrm{RuO}_{2}$ and $\mathrm{MnO}_{x}$ by combining the electrochemical quartz crys-

\section{Introduction}

Water electrolysis is set to play a key role in the provision of solar fuels, as a sustainable substitute for fossil fuels. ${ }^{[1]}$ Polymer electrolyte membrane (PEM) electrolysers are particularly wellsuited towards the localised storage of renewables such as wind or solar, which are inherently intermittent. It turns out that the majority of the efficiency losses on these devices can be traced back to the oxygen evolution reaction (OER).$^{[2,3]}$ Consequently, it is critical that the OER catalyst has a sufficiently high activity, to minimise these losses, and that this activity is stable over the whole lifetime of the catalyst. This is particularly challenging, not only because the anode operates at inherently oxidising potentials, but also as a result of the acidic electrolyte of PEM electrolysers. At present, only $\operatorname{IrO}_{x}$ and $\mathrm{RuO}_{x}$ based materials show reasonable activity and stability under such conditions. ${ }^{[4,5]}$ The best-performing catalysts in acidic media are shown in the Tafel plot in Figure $1 \mathrm{a}$, which provides an overview of the current state of the art, clearly dominated by oxide catalysts based on the scarce elements $\mathrm{Ru}$ and Ir. However, should PEM electrolysis make a true impact to the global energy landscape, it will need to be scaled up to the terawatt level ${ }_{i}^{[6]}$ consequently, the loading of the precious metals required to catalyse the OER should be decreased drastically or eliminated altogether. ${ }^{[7,8]}$ In principle, the proton-con-

\footnotetext{
[a] R. Frydendal, E. A. Paoli, B. P. Knudsen, Dr. B. Wickman, Dr. P. Malacrida,

Prof. I. E. L. Stephens, Prof. I. Chorkendorff

Center for Individual Nanoparticle Functionality

Department of Physics, Technical Univ. of Denmark

DK-2800 Kongens Lyngby (Denmark)

E-mail: ifan.stephens@fysik.dtu.dk ibchork@fysik.dtu.dk

[b] Dr. B. Wickman

Department of Applied Physics

Chalmers University of Technology

SE-41296 Göteborg (Sweden)
}

tal microbalance (EQCM) with inductively coupled plasma mass spectrometry (ICP-MS). We show that a meaningful estimation of the stability cannot be achieved based on purely electrochemical tests. On the catalysts tested, the anodic dissolution current was four orders of magnitude lower than the total current. We propose that even if long-term testing cannot be replaced, a useful evaluation of the stability can be achieved with short-term tests by using EQCM or ICP-MS.
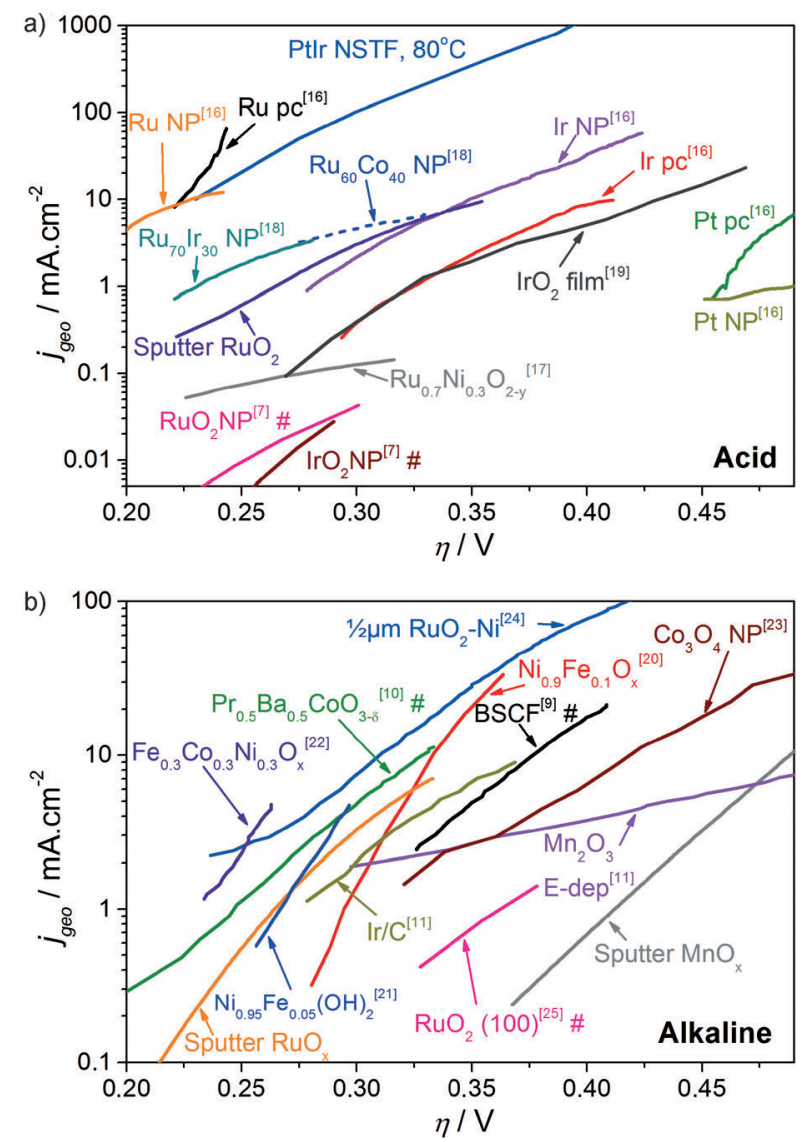

Figure 1. Overview of the state of the art for the oxygen evolution reaction: a) In acid media. Data adapted from: Present work for sputtered $\mathrm{RuO}_{2}{ }^{\left[{ }^{[6]}\right.}$ for $\mathrm{Ru}, \mathrm{Ir}$ and Pt polycrystalline (pc) and nanoparticles (NP), ${ }^{[17]}$ for $\mathrm{Ru}_{0.7} \mathrm{Ni}_{0.3} \mathrm{O}_{2-y}$ nanocrystals, ${ }^{[18]}$ for RuCo and Rulr NP, ${ }^{[19]}$ for $\mathrm{IrO}_{2}$ film and ${ }^{[7]}$ for $\mathrm{RuO}_{2}$ and $\mathrm{IrO}_{2}$ NP (\# normalised to oxide area). b) In alkaline media. Data adapted from: Present work for sputtered $\mathrm{MnO}_{x}$, from this group for sputtered $\mathrm{RuO}_{x^{\prime}}{ }^{[20]}$ for $\mathrm{Ni}_{0.9} \mathrm{Fe}_{0.1} \mathrm{O}_{x^{\prime}}{ }^{[21]}$ For $\mathrm{Ni}_{0.95} \mathrm{Fe}_{0.05}(\mathrm{OH})_{2}{ }^{[22]}$ for $\mathrm{Fe}_{0.3} \mathrm{Co}_{0.3} \mathrm{Ni}_{0.3} \mathrm{O}_{x \prime}{ }^{[9]}$ for $\mathrm{Ba}_{0.5} \mathrm{Sr}_{0.5} \mathrm{Co}_{0.8} \mathrm{Fe}_{0.2}$ (\# normalised to oxide area), ${ }^{[10]}$ for $\operatorname{Pr}_{0.5} \mathrm{Ba}_{0.5} \mathrm{CoO}_{3-\delta}$ (\# normalised to oxide area), ${ }_{1}^{[1]]}$ for Ir/C and $\mathrm{Mn}_{2} \mathrm{O}_{3}$ E-dep, ${ }^{[23]}$ for $\mathrm{CO}_{3} \mathrm{O}_{4} \mathrm{NP}_{r}^{[24]}$ for $\mathrm{RuO}_{2}-\mathrm{Ni}$ and ${ }^{[25]}$ for $\mathrm{RuO}_{2}$ (100) (normalised to oxide area). 
ducting polymers used in PEM electrolysers could be replaced by hydroxide-conducting membranes; indeed, several materials have recently been discovered in alkaline electrolytes with a catalytic activity at least as high as that of $\mathrm{RuO}_{x}$ and $\mathrm{IrO}_{x}{ }^{[9-12]}$ In Figure $1 \mathrm{~b}$, the best-performing OER catalysts in alkaline media are shown in a unified Tafel plot (it should be noted that in this plot the activity of some of the catalysts has been reported as a current density normalised according to the microscopic surface area, denoted by the symbol \# in the plot, whereas other catalysts have been normalised according to the geometric surface area). It is clear from the plot that the most active catalysts are primarily based on $\mathrm{Ni}$ or Co. Even so, the use of alkaline polymeric membranes comes at the cost of increased overpotential for hydrogen evolution, and lower membrane conductivity and stability. ${ }^{[13-15]}$

Regardless of the $\mathrm{pH}$ of the electrolyte, robust OER catalyst benchmarks are required that allow a straightforward comparison of catalyst performance between different experimental groups. ${ }^{[4,7]}$ Critical parameters include: 1$)$ the geometric activity, that is, the current normalised according to the geometric or projected area, 2) the mass activity, that is, the current per unit mass precious metals, 3) the specific activity, the current normalised according to the microscopic area, and 4) the stability of the catalyst.

In a commercial device, it is essential that the geometric activity is maximised, to minimise overpotentials. Moreover, should precious metal oxides be employed, a high geometric activity should not be reliant on significant loadings of scarce elements, that is, the mass activity should also be maximised. Both the geometric activity and mass activity can be maximised by employing materials with a high specific activity and a high surface area. However, to judge whether a material is intrinsically active for a reaction, knowledge of the specific activity becomes important. This metric, in turn, is dependent on an accurate knowledge of the electrochemically active surface area, which is challenging to measure on oxides. Alternatively, the catalyst activity can be assessed using smooth thin films, where the microscopic surface area is as close as possible to the geometric surface area. ${ }^{[20,26,27]}$

The procedures for assessing the stability of OER catalysts are not well established in the literature; this is in contrast to the reverse of the OER, the oxygen reduction reaction (ORR), where detailed tests for assessing the catalyst stability have been developed to simulate the conditions required for automotive applications ${ }^{[28]}$. Thus far, most researchers have assessed the stability under OER conditions for a limited number of hours, by performing chronopotentiometry at a constant current density or chronoamperometry at a constant potential. However, it remains questionable whether such measurements can provide the basis upon which one could judge the longterm performance of a catalyst in a real device over the required lifetime, that is, a number of years.

A number of methods exist to monitor catalyst corrosion. ${ }^{[29]}$ Microscopic techniques, such as scanning tunneling microsco$\mathrm{py}^{[30,31]}$ and transmission electron microscopy, ${ }^{[32-35]}$ can monitor changes in the electrode morphology and structure. On the other hand, macroscopic techniques can be applied to deter- mine the corrosion rates; these include the rotating ring disk electrode (RRDE; for example, for monitoring the anodic dissolution of $\left.\mathrm{RuO}_{2}{ }^{[36,37]}\right)$, the quartz crystal microbalance, ${ }^{[38]}$ and inductively coupled plasma mass spectrometry (ICP-MS). ${ }^{[39-41]}$ Nonetheless, as of yet, no standardized protocols for assessing the stability under OER conditions have emerged.

Herein, we present guidelines for establishing the stability of OER electrocatalysts. By combining standard RDE tests with electrochemical quartz crystal microbalance ${ }^{[42]}$ (EQCM) measurements and inductively coupled plasma mass spectrometry (ICP-MS), we provide a detailed description of corrosion processes that take place in parallel to the OER. The catalysts investigated are $\mathrm{RuO}_{2}$ and $\mathrm{MnO}_{x} \cdot \mathrm{RuO}_{2}$ is an extensively studied material with a high activity in acidic electrolyte. ${ }^{[16,43-45]}$ However, the stability of $\mathrm{RuO}_{2}$ is limited at high overpotentials. $\mathrm{MnO}_{x}$ has been proposed as a more abundant and inexpensive alternative to $\mathrm{RuO}_{2},{ }^{[46-49]}$ not only is it active for the OER, but also for the ORR, opening up possibilities for its use in regenerative fuel cells. ${ }^{[50]}$ Manganese can form numerous oxides and many of these have been reported active for OER in alkaline and neutral electrolytes. ${ }^{[51]}$ However, as for ruthenium dioxide, the stability can be an issue at high overpotentials.

\section{Experimental Section}

\section{Preparation of Thin Films}

Thin $\mathrm{MnO}_{x}$ and $\mathrm{RuO}_{2}$ films were prepared by reactive sputter deposition on Au polycrystals and EQCM crystals. The deposition rates were calibrated with an in-chamber QCM. Prior to deposition, the samples were sonicated in acetone, isopropanol, and then Millipore water $(18.2 \mathrm{M} \Omega) . \mathrm{RuO}_{2}$ films were deposited at $300^{\circ} \mathrm{C}$ and 3 mTorr with a power of $50 \mathrm{~W}$ using an argon and oxygen flow at a ratio of $5: 2$, with a metallic Ru target. $\mathrm{MnO}_{x}$ films were deposited at $200^{\circ} \mathrm{C}, 5 \mathrm{mTorr}$, and $140 \mathrm{~W}$ with an argon and oxygen flow at a ratio of $5: 1$, and a metallic Mn target. The EQCM crystals were purchased from Stanford Research Systems (QCM200) and consist of a gold film deposited onto AT-cut quartz with a titanium layer in between for improved adhesion. The top electrode, functioning as working electrode for the electrochemical measurements, has a geometrical surface area of $1.37 \mathrm{~cm}^{2}$. The bottom electrode is smaller, $0.38 \mathrm{~cm}^{2}$, and the QCM is sensitive only in the overlapping region of the top and bottom electrodes. This means that approximately $28 \%$ of the electrochemically active layer is sensitive to the QCM measurement. The frequency change is converted to mass change using the Sauerbrey equation, as explained below. In this equation, a homogeneous mass change across the electrode is assumed. Because of the semiconducting nature of manganese oxides, we used a mask to confine the $\mathrm{MnO}_{x}$ area to where the QCM is sensitive (the central $0.38 \mathrm{~cm}^{2}$ of the top electrode). This was done to diminish effects of local potential differences, for example, caused by gradients in film thickness. The remaining part of the gold film was covered with $\mathrm{TiO}_{2}$, which introduced negligible currents and no frequency change during the stability tests. As $\mathrm{RuO}_{2}$ is expected to be a metallic conductor, all of the gold film was covered with $\mathrm{RuO}_{2}$. The $\mathrm{Au}$ polycrystalline electrodes $\left(0.196 \mathrm{~cm}^{2}\right)$ used in RDE tests were polished prior to deposition with $0.25 \mu \mathrm{m}$ diamond paste, then plasma cleaned in argon and annealed to $700^{\circ} \mathrm{C}$ in two consecutive cycles. The targets for sputtering had a $99.95 \%$ purity and were purchased from AJA International. 


\section{Electrochemical Tests}

The electrochemical tests on $\mathrm{RuO}_{2}$ were performed in a glass cell with $0.05 \mathrm{M} \mathrm{N}_{2}$-saturated $\mathrm{H}_{2} \mathrm{SO}_{4}$ (Merck Suprapur $96 \%$, diluted with 18.2 $\mathrm{M} \Omega$ Millipore water) at room temperature. The tests on $\mathrm{MnO}_{x}$ were performed in a two-compartment Teflon cell with $1 \mathrm{M} \mathrm{N} \mathrm{N}_{2}$-saturated $\mathrm{KOH}$ (Merck Suprapur 99.995, diluted with $18.2 \mathrm{M} \Omega$ Millipore water) at room temperature. For the tests in sulfuric acid, a Hg/ $\mathrm{HgSO}_{4}$ reference electrode was used, whereas for the tests in $\mathrm{KOH}$, a $\mathrm{Hg} / \mathrm{HgO}$ in $20 \mathrm{wt} \% \mathrm{KOH}$ reference electrode was used. The reference-electrode potentials were measured with respect to a reversible hydrogen electrode (RHE) by bubbling 1 bar hydrogen over a clean Pt surface in the same electrolyte. In both electrolytes, graphite rods were used as counter electrodes. All the data is presented using the RHE scale and corrected for Ohmic losses, found from the fitted high-frequency intercept measured using electrochemical impedance spectroscopy over the range of $1-200000 \mathrm{~Hz}$ at a DC potential of $10 \mathrm{mV}$. The Ohmic drop for tests in $0.05 \mathrm{M}$ $\mathrm{H}_{2} \mathrm{SO}_{4}$ was in the range of $15-18 \Omega$, whereas the tests in $1 \mathrm{M} \mathrm{KOH}$ comprised an Ohmic drop in the range of 3-5 $\Omega$. For chronoamperometry measurements, the Ohmic drop was compensated at $85 \%$ using the Bio-Logic software EC-lab method MIR. Mass changes from EQCM measurements were calculated using the Sauerbrey equation with $C_{\mathrm{f}}=(56.6 \pm 2.8) \mathrm{Hzcm}^{2} \mu \mathrm{g}^{-1,[52]}$ this value was calibrated by the electrodeposition of silver onto the Au-coated quartz crystal, repeated six times. ${ }^{[53]}$ Each stability test performed by both EQCM and ICP-MS was repeated four times.

Since gold is not expected to be stable at high oxidative potentials, ${ }^{[40]}$ we did not perform reference measurements with the bare EQCM crystals. Instead, the gold was coated by the catalyst thin film, as described above, and we measured the amount of gold in the electrolyte after OER tests. Based on two-hour tests at $1.9 \mathrm{~V}_{\text {RHE }}$ for three $\mathrm{MnO}_{x}$ samples, the increase of gold was less than $9 \mathrm{ng} \mathrm{cm}^{-2}$ or equivalent to less than $0.6 \mathrm{~Hz}$. We therefore assumed that $\mathrm{Au}$ is sufficiently masked from the electrolyte.

At high current densities, gas formation on the electrode affects the frequency measurement; however, since the electrode was oriented vertically, the bubbles moved upwards and did not accumulate on the active area. While the bubble formation could cause some noise in the measurement, it would not have an effect on the trends observed over two-hour experiments.

\section{Characterisation Methods}

ICP-MS experiments were performed with equipment from Thermo Fisher Scientific, model iCAP-QC ICP-MS. Samples were taken out of the electrolyte before and after each measurement using a pipette. For tests in $0.05 \mathrm{M} \mathrm{H}_{2} \mathrm{SO}_{4}$ the samples were analysed without further dilution, whereas for a $40 \mathrm{~nm} \mathrm{RuO}{ }_{2}$ on EQCM sample.
$1 \mathrm{M} \mathrm{KOH}$, the samples were diluted to $0.1 \mathrm{M}$ to protect the ICP-MS components. For the quantitative analysis, calibration tests were performed using diluted solutions of $\mathrm{Mn}$ or $\mathrm{Ru}$, made from standards with $1000 \mu \mathrm{g}_{\text {metal }} \mathrm{mL}^{-1}$ purchased from SCP Science. Calibrations were made with at least three concentrations. These were prepared in the range of 0.1 to $10 \mu \mathrm{L} \mathrm{L}^{-1}$ since the concentrations of $\mathrm{Mn}$ and $\mathrm{Ru}$ in the investigated electrolytes are all within that range. The calibration curves obtained could all be fitted to a linear curve with an $R^{2}$ of 0.99 or better. To calculate the total mass loss with ICP-MS, the volume of the electrolyte was measured for each experiment. For measurements with the two-compartment Teflon cell, only the volume of the compartment containing the working electrode was used. It was confirmed with a separate ICP-MS test that the amount of metal in the reference-electrode compartment was negligible. The thin films were evaluated by X-ray photoelectron spectroscopy using a Theta Probe instrument (Thermo Scientific) where the base pressure was $5 \times$ $10^{-10} \mathrm{mbar}$. The $\mathrm{X}$-ray source was monochromatized $\mathrm{Al}_{\mathrm{Ka}}$ $(1486.7 \mathrm{eV})$. Furthermore, the thin films were analysed by X-ray diffraction (XRD) using a PANanalytical X'pert PRO equipment with an $\mathrm{X}$-ray wavelength of $1.54 \AA$ for the $\mathrm{Cu}_{\mathrm{K} \alpha}$ line.

\section{Results and Discussion}

To determine the structure of the two oxides, we performed glancing-angle XRD measurements. In Figure $2 \mathrm{a}$, the diffractograms for $\mathrm{RuO}_{2}$ and $\mathrm{MnO}_{x}$ are shown, together with literature references and a measurement for the glass substrate. For the $\mathrm{RuO}_{2}$ film, the diffractogram obtained was consistent with a rutile $\mathrm{RuO}_{2}$ structure, ${ }^{[54]}$ whereas for $\mathrm{MnO}_{x}$, no significant peaks were found, indicating that the film is amorphous. To
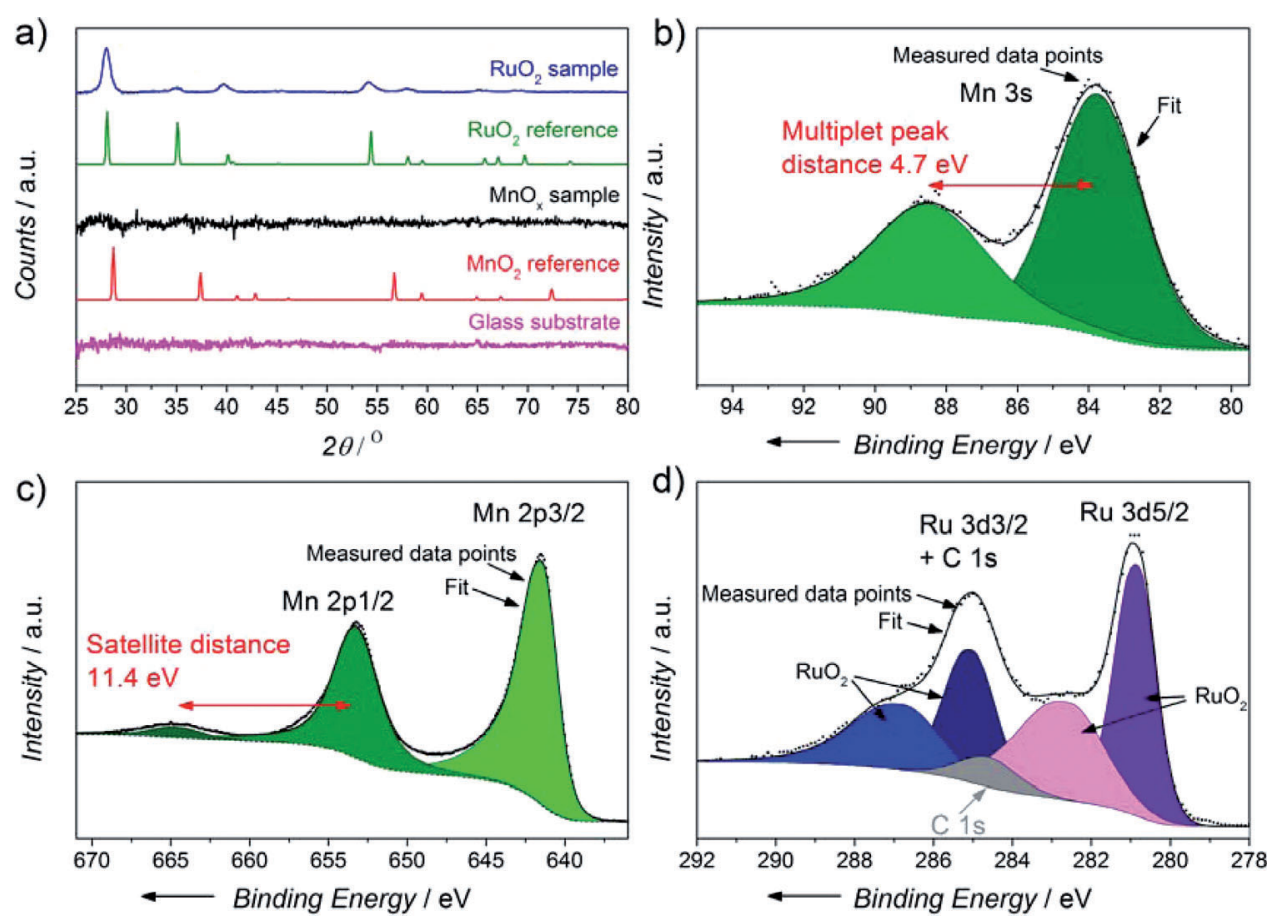

Figure 2. a) XRD diffractograms for $\mathrm{RuO}_{2}, \mathrm{MnO}_{x}$ and the substrate, together with literature references. The literature data for $\mathrm{RuO}_{2}$ is from Ref. [54] and that for $\mathrm{MnO}_{2}$ from Ref. [59]. b) XPS spectra of the Mn 3s region for a $40 \mathrm{~nm} \mathrm{MnOx}$ on EQCM sample. The red arrow indicates the difference in binding energy for the Mn $3 \mathrm{~s}$ multiplet splitting. c) XPS spectra of the Mn $2 p$ region for a $40 \mathrm{~nm} \mathrm{MnO}$ on EQCM sample. The red arrow indicates the distance from the Mn 2p1/2 peak to its corresponding satellite. d) XPS spectra of the Ru 3d core level region for 
further characterise the composition, XPS analyses were carried out. The results can be seen in Figure $2 \mathrm{~b}-\mathrm{d}$ for $\mathrm{MnO}_{x}$ and $\mathrm{RuO}_{2}$, respectively. The $\mathrm{MnO}_{x}$ film was evaluated using the $\mathrm{Mn}$ $3 \mathrm{~s}$ multiplet splitting and $\mathrm{Mn} 2 \mathrm{p}_{1 / 2}$ distance between the main peak and its satellite. ${ }^{[55,56]}$ The former was found to be $4.7 \mathrm{eV}$ and the latter $11.4 \mathrm{eV}$, suggesting that the stoichiometry is consistent with $\mathrm{MnO}_{2}$, which is also the most stable surface for $\mathrm{Mn}$ under OER conditions. ${ }^{[57]}$ The $\mathrm{RuO}_{2}$ film was evaluated based on the position and area of the Ru $3 \mathrm{~d}$ lines, which matched with $\mathrm{RuO}_{2}$ literature references. ${ }^{[58]}$

The electrochemical results are described in experimental order to ensure ease of reproducibility. As a first step, the activity of each sample was evaluated by using standard cyclic voltammetry at $5 \mathrm{mVs}^{-1}$. Representative results can be seen in Figure 3 for both RDE and EQCM setups. A useful figure of merit is the overpotential needed to sustain $10 \mathrm{~mA} \mathrm{~cm}^{-2} \cdot{ }^{[3]}$ For $\mathrm{RuO}_{2}$ in $0.05 \mathrm{M} \mathrm{H}_{2} \mathrm{SO}_{4}$ it is $(354 \pm 8) \mathrm{mV}$ whereas for $\mathrm{MnO}_{x}$ it is $(494 \pm 6) \mathrm{mV}$, using the results from the RDE setup, based on two independent measurements for each oxide. These overpotentials are comparable to earlier reports in the literature, even though the films are only $40 \mathrm{~nm}$ thick and deposited onto smooth substrates, likely resulting in lower surface areas compared to samples made by electrodeposition or thermally prepared oxides. The activity obtained in the EQCM setup is slightly lower at high overpotentials for both samples; this discrepancy could result from a less facile bubble removal, compared to the rotating disk. However, the onsets of OER are the
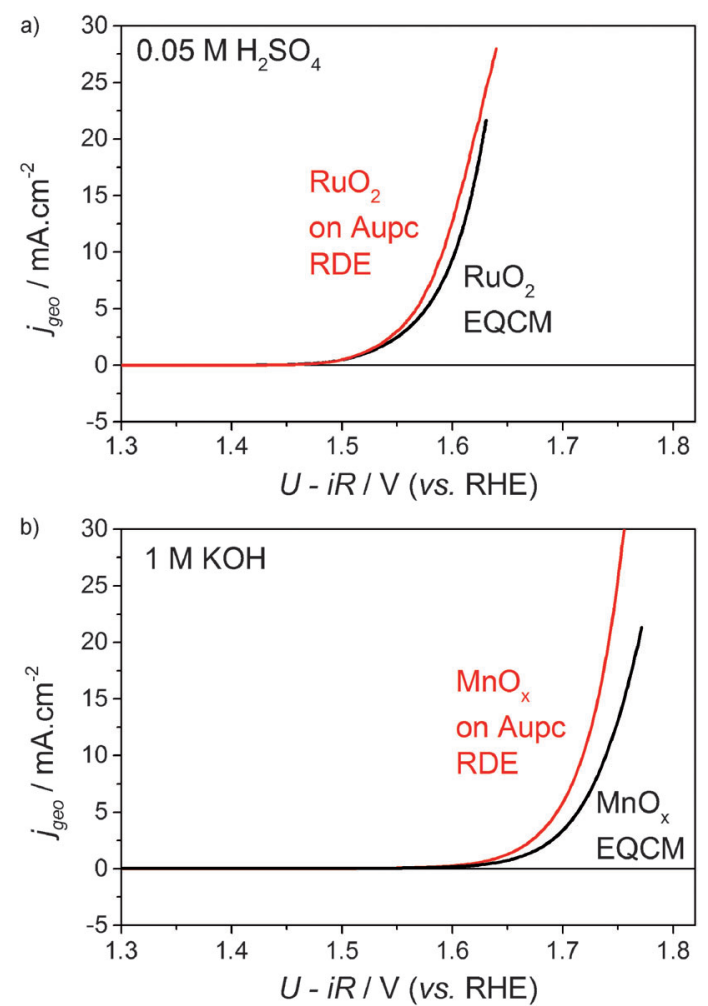

Figure 3. Cyclic voltammetry curves at room temperature for: a) $40 \mathrm{~nm} \mathrm{RuO}_{2}$ in $0.05 \mathrm{M} \mathrm{N}_{2}$-saturated $\mathrm{H}_{2} \mathrm{SO}_{4}$. b) $40 \mathrm{~nm} \mathrm{MnO}_{x}$ in $1 \mathrm{M} \mathrm{N}_{2}$-saturated $\mathrm{KOH}$. The scan rate was $5 \mathrm{mV} \mathrm{s}^{-1}$ and $1600 \mathrm{RPM}$ (revolutions per minute) were used in the RDE tests. The current was normalised to the geometric area. The first anodic sweeps are shown. same in the two setups. Next, the Ohmic loss was evaluated by using impedance spectroscopy, followed by a stabilisation period during which the measured resonance frequency for the EQCM settled at a constant level. We observed that the frequency reading became stable after approximately 30 to $60 \mathrm{~min}$, presumably due to temperature equilibration or equipment vibrations from cell assembly. Our criterion for establishing the stability was that the frequency would change less than $1 \mathrm{~Hz}$ over $15 \mathrm{~min}$, which corresponds to a lower change than for any subsequent OER test. In the case of the $\mathrm{RuO}_{2}$, the films were stabilised at $1.23 \mathrm{~V}_{\mathrm{RHE}}$ whereas the $\mathrm{MnO}_{x}$ films were
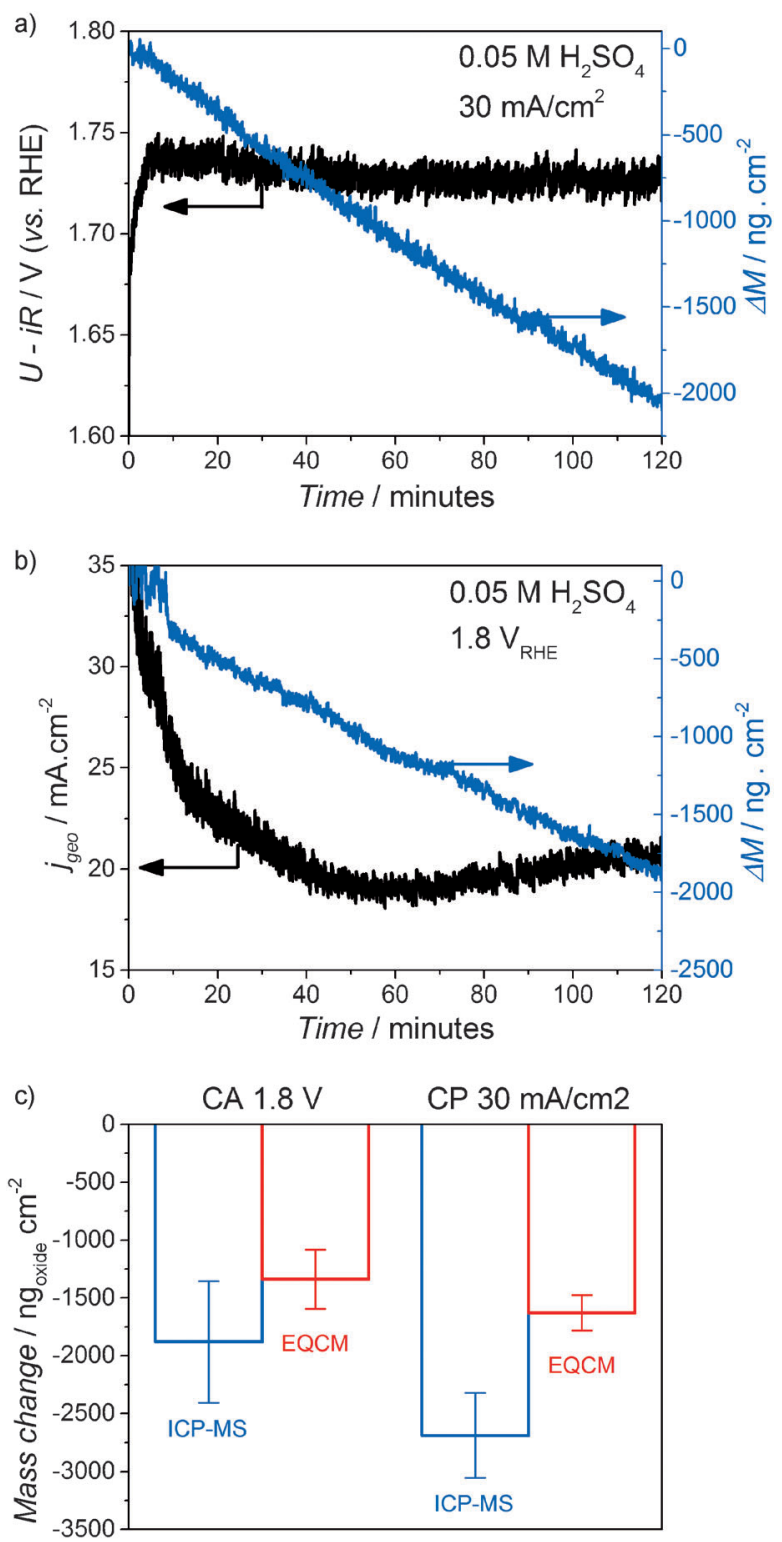

Figure 4. a) Chronopotentiometry at $30 \mathrm{mAcm}^{-2}$ for $40 \mathrm{~nm} \mathrm{RuO}$ by using EQCM in $0.05 \mathrm{M} \mathrm{N}_{2}$-saturated $\mathrm{H}_{2} \mathrm{SO}_{4}$ at room temperature. The black line indicates the measured potential and the blue line indicates the change in mass based on in situ resonance frequency measurements. b) Chronoamperometry at $1.8 \mathrm{~V}_{\mathrm{RHE}}$ for $40 \mathrm{~nm} \mathrm{RuO}$ by using EQCM in $0.05 \mathrm{M} \mathrm{N} \mathrm{N}_{2}$-saturated $\mathrm{H}_{2} \mathrm{SO}_{4}$ at room temperature. c) Comparison of the mass change found from EQCM and ICP-MS based on four separate experiments. The mass loss from the ICP-MS measurements was adjusted to the equivalent $\mathrm{RuO}_{2}$ mass (rather than the Ru mass) for more direct comparison to EQCM measurements. 
stabilised at $1.4 \mathrm{~V}_{\mathrm{RHE}}$; in both cases these potentials were chosen on the basis that the dioxide phases would be stable. ${ }^{[59]}$ After the initial period of cycling, impedance measurement and stabilisation, samples for ICP-MS analysis were taken. From four measurements on each catalyst we found an average of $(123 \pm 60) \mathrm{ng}_{\text {oxide }} \mathrm{Cm}^{-2} \quad \mathrm{RuO}_{2}$ and (472 \pm 240) $\mathrm{ng}_{\text {oxide }} \mathrm{Cm}^{-2} \mathrm{MnO}_{2}$ present in the solution prior to further testing. These results indicate that the initial cyclic voltammetry induces mass losses for both materials, these losses being more significant for $\mathrm{MnO}_{x}$. During subsequent corrosion measurements, to assess the amount of $\mathrm{Ru}$ or $\mathrm{Mn}$ dissolved during the test, the initial amount of dissolved $\mathrm{Ru}$ or $\mathrm{Mn}$ at the start of the measurement was subtracted from the final amount.

Once the frequency had stabilised, first chronoamperometry, $C A$, and then chronopotentiometry, $C P$, measurements were started. For $\mathrm{RuO}_{2}$, we measured $\mathrm{CA}$ at $1.8 \mathrm{~V}_{\mathrm{RHE}}$ and $\mathrm{CP}$ at $30 \mathrm{~mA} \mathrm{~cm}^{-2}$. These parameters were chosen to ensure that the potential was positive of the reversible potential for $\mathrm{RuO}_{4}$ formation, $1.39 \mathrm{~V}_{\mathrm{RHE}}{ }^{\left[{ }^{[60]}\right.}$ under standard conditions. For $\mathrm{MnO}_{x}$, potentials at 1.8 and $1.9 \mathrm{~V}_{\mathrm{RHE}}$ and a current density of $20 \mathrm{mAcm}^{-2}$ were chosen to be positive of the potential for $\mathrm{MnO}_{4}^{-}$formation. ${ }^{[60]}$ All stability tests were carried out for $2 \mathrm{~h}$. We have observed that longer term tests tend to yield a poorer reproducibility; this could be a result of thickness gradients giving rise to local conductivity issues, exposed substrate, redeposition of dissolved species or precipitation. It should also be noted that corrosion mechanisms are highly dependent on the material. ${ }^{[39]}$ The degradation of some materials may actually be accelerated by potential cycling (as shown by Mayrhofer and co-workers to be the case for $\mathrm{Pt}$, by combining cyclic voltammetry with online ICP measurements ${ }^{[61]}$ ). Consequently, to study the resistance to corrosion of such materials, potentiodynamic-rather than potentiostatic-tests would be necessary.

\subsection{Stability of $\mathrm{RuO}_{2}$}

In the case of $\mathrm{RuO}_{2}$, the results from chronopotentiometry and chronoamperometry can be seen in Figure $4 \mathrm{a}$,b. Chronopotentiometry, as a technique, should correspond to the performance for a constant hydrogen production load on an electrolyser. The extra overpotential needed to sustain the hydrogen production is directly correlated to energy loss. In Figure $4 \mathrm{a}$, it can be seen that $\mathrm{RuO}_{2}$ can maintain a stable performance, which changes only slightly during $2 \mathrm{~h}$. However, looking at the mass change associated with the test, it is clear that there is a constant mass loss. This mass loss is equivalent to 4.8 monolayers $(\mathrm{ML})$ per hour assuming the density and lattice parameters of (110) $\mathrm{RuO}_{2}$ layers. ${ }^{[54]}$ Figure $4 \mathrm{~b}$ shows the results of the chronoamperometry measurement. The potential is held constant throughout the measurement; since the current depends exponentially on the potential, any deactivation shows up more clearly than in a chronopotentiometry measurement. A constant potential at $1.8 \mathrm{~V}_{\mathrm{RHE}}$ yields a mass loss equivalent of $4.4 \mathrm{ML}$ per hour. With this rate, it would take approximately $29 \mathrm{~h}$ to corrode all of the $40 \mathrm{~nm}$ film. Assuming that the corrosion proceeds in accordance to $\mathrm{RuO}_{2}+2 \mathrm{H}_{2} \mathrm{O} \rightarrow$ $\mathrm{RuO}_{4(\text { aq })}+4 \mathrm{H}^{+}+4 \mathrm{e}^{-},{ }^{[36]}$ a dissolution rate of $4 \mathrm{ML}$ per hour would be equivalent to $0.6 \mu \mathrm{Acm}^{-2}$, that is, more than four orders of magnitude lower than the oxygen evolution current density. In principle, the transient formation of $\mathrm{RuO}_{4}{ }^{[36]}$ could be detected with a rotating ring disk electrode setup; however, the necessary current sensitivity would be unrealistic. We also analysed the solution by ICP-MS after the electrochemical tests; Figure 4c compares the EQCM and ICP-MS results. The mass losses found from the ICP-MS measurements shown in Figure $4 \mathrm{C}$ are converted to $\mathrm{RuO}_{2}$ equivalent since ICP-MS is only sensitive towards single elements and not the initial oxides. Comparing the two methods, there are differences for
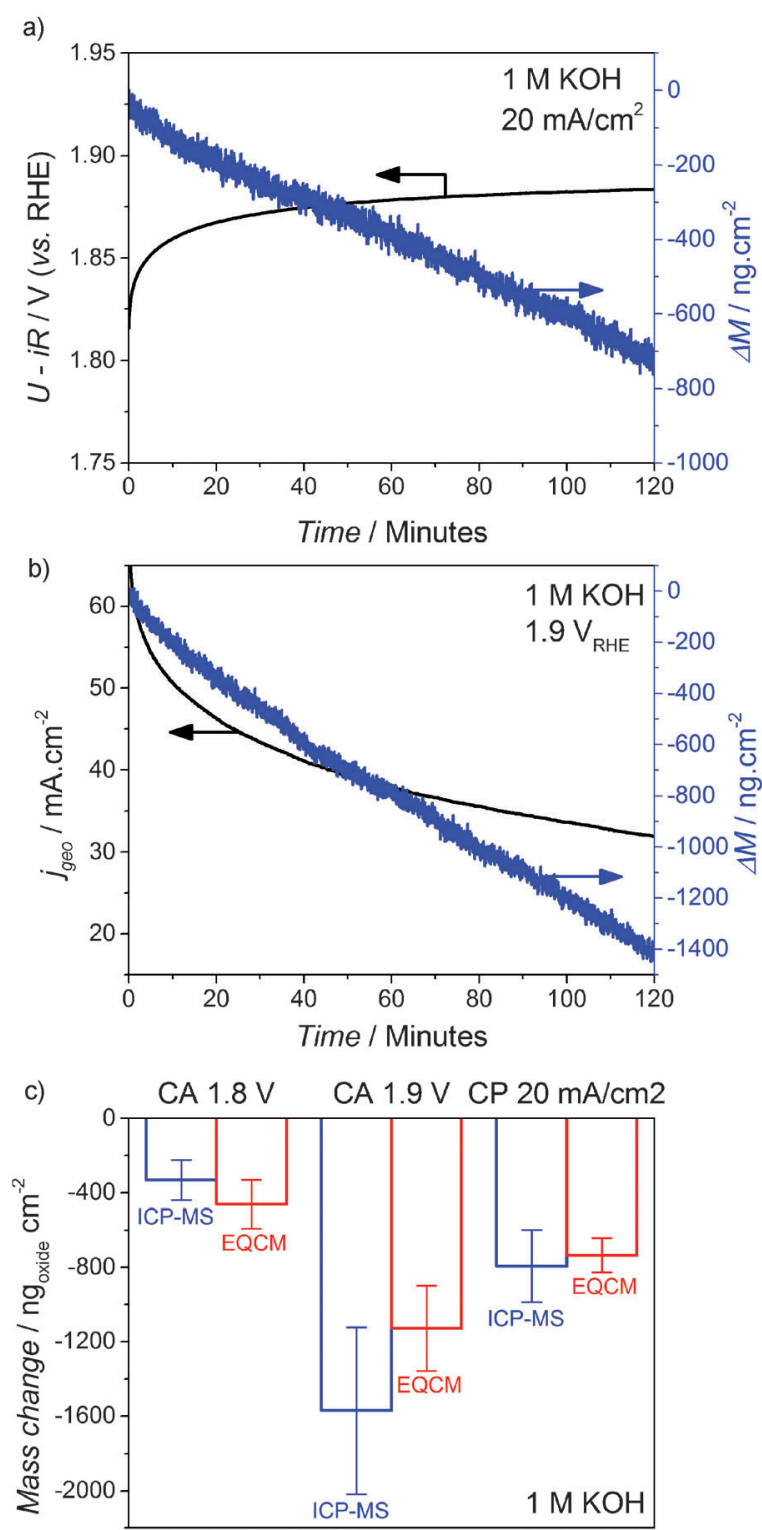

Figure 5. a) Chronopotentiometry at $20 \mathrm{mAcm}^{-2}$ for $40 \mathrm{~nm} \mathrm{MnO}$ by using EQCM in $1 \mathrm{M} \mathrm{N}_{2}$-saturated $\mathrm{KOH}$ at room temperature. The black line indicates the measured potential and the blue line indicates the change in mass based on in situ resonance frequency measurements. b) Chronoamperometry at $1.9 \mathrm{~V}_{\mathrm{RHE}}$ for $40 \mathrm{~nm} \mathrm{MnO}$ by using EQCM in $1 \mathrm{M} \mathrm{N}_{2}$-saturated $\mathrm{KOH}$ at room temperature. c) Comparison of the mass change found from EQCM and ICP-MS based on four separate experiments. The mass loss from the ICP-MS measurements was adjusted to the equivalent $\mathrm{MnO}_{2}$ mass (rather than the $\mathrm{Mn}$ mass), for more direct comparison to EQCM measurements. 
both tests. The losses evaluated by ICP-MS are higher than what is seen from the EQCM method. This could be due to the fact that EQCM is only sensitive to about $28 \%$ of the catalytically active area, as descibed in the experimental section. We assume a homogeneous mass loss across the electrode but an inhomogenous current distribution could result in a wrong estimation. On the other hand, ICP-MS is sensitive to losses from the entire electrode area, which is likely to give a more accurate evaluation.

\subsection{Stability of $\mathrm{MnO}_{x}$}

Chronopotentiometry and chronoamperometry tests were also carried out for $\mathrm{MnO}_{x}$ in alkaline solution, $1 \mathrm{M} \mathrm{KOH}$, as shown on Figure $5 \mathrm{a}, \mathrm{b}$. Compared to the results for $\mathrm{RuO}_{2}$, the chronopotentiometry test results in a larger increase of potential during the two hours. The graph in Figure $5 \mathrm{a}$ also shows the importance of choosing an axis length spanning only the relevant data range so the change is easily spotted. However, on the basis of the chronoamperometry measurement in Figure $5 \mathrm{~b}$, the deactivation is even clearer because of the exponential behaviour of the current density as a function of the overpotential. However, in both measurements, a constant mass loss takes place in parallel with the oxygen evolution current. At $1.9 \mathrm{~V}_{\mathrm{RHE}}$, the loss of $1128 \mathrm{ng} \mathrm{cm}^{-2}$ is equivalent to about 3.9 ML per hour, assuming the density and lattice parameters of rutile (110) $\mathrm{MnO}_{2}$ layers, ${ }^{[59]}$ while a constant current at $20 \mathrm{mAcm}^{-2}$ leads to a loss of about 2.6 ML per hour. ${ }^{1}$ Assuming that the losses are due to anodic dissolution, that is, $\mathrm{MnO}_{2}+2 \mathrm{H}_{2} \mathrm{O} \rightarrow \mathrm{MnO}_{4}^{-}{ }_{\text {(aq) }}+4 \mathrm{H}^{+}+3 \mathrm{e}^{-}$, ${ }^{[60]}$ this rate would be equivalent to a current density of $0.35 \mu \mathrm{Acm}^{-2}$, more than four orders of magnitude lower than the total current. ${ }^{2}$ The mass losses were also evaluated by ICPMS after each measurement, as shown in Figure $5 c$. We note that the error bars are rather large. Nonetheless, the two methods show an overall agreement. Extrapolating the data here, the time required to completely corrode a $40 \mathrm{~nm}$-thick $\mathrm{MnO}_{x}$ film would be approximately $36 \mathrm{~h}$ at a constant potential of $1.9 \mathrm{~V}_{\mathrm{RHE}}$. From another perspective, a confirmation of stability for a given catalyst would require that a specific lifetime can

\footnotetext{
${ }^{1}$ We assumed $a \mathrm{MnO}_{2}$ composition on the basis of our XPS analysis. Although the XRD experiments suggested that the films are amorphous, we take the view that the rutile (110) plane provides a reasonable approximation of the surface termination. Should we have chosen a different structure, the interplanar distance would always be between 2-4 A, varying the loss in monolayers by less than a factor of two. The exact surface termination will not change our overall conclusions.

${ }^{2}$ It is conceivable that $\mathrm{MnO}_{2}$ dissolves via a two-electron process to $\mathrm{MnO}_{4}{ }^{2-,}{ }^{[60]}$ which would lead to a corrosion current density of $0.26 \mu \mathrm{Acm}^{-2}$, rather than $0.35 \mu \mathrm{Acm}^{-2}$. Regardless, this will not change the picture presented herein, as the anodic current would still be negligible in comparison to the overall dissolution current.
}

be ensured. As an example, a lifetime of five years for a $40 \mathrm{~nm}$ film corresponds to a maximum of $0.02 \AA$ dissolved material in a two-hour test. This rate for a $\mathrm{RuO}_{2}$ catalyst on a $1 \mathrm{~cm}^{2}$ electrode in $100 \mathrm{~mL}$ of electrolyte results in a less than $2 \mathrm{ppt}$ concentration in the ICP-MS analysis. Such concentrations approach the limit of detection, that is, $0.4 \mathrm{ppt}$ for $\mathrm{Ru}^{\left[{ }^{[62]}\right.}$ which complicates meaningful extrapolation. Therefore, a comprehensive lifetime evaluation should be accompanied by a long-term test. In Table 1, the relevant stability metrics and standard deviations are listed together with the OER activity of the thin films.

\begin{tabular}{|c|c|c|c|c|c|c|}
\hline Sample ${ }^{[a]}$ & $\begin{array}{l}\eta_{10 \mathrm{mAcm}^{-2}}[\mathrm{mV}] \\
\text { from RDE }\end{array}$ & & $\begin{array}{l}\Delta M_{1.8 \mathrm{~V}(\mathrm{RHE})} 2 \mathrm{~h} \\
{\left[\mathrm{ng}_{\text {oxide }} \mathrm{cm}^{-2}\right]}\end{array}$ & $\begin{array}{l}\Delta M_{1.9 \mathrm{~V}(\mathrm{RHE})} 2 \mathrm{~h} \\
{\left[\mathrm{ng}_{\text {oxide }} \mathrm{cm}^{-2}\right]}\end{array}$ & $\begin{array}{l}\Delta M_{30 \mathrm{mAcm}^{-2}} 2 \mathrm{~h} \\
{\left[\mathrm{ng}_{\text {oxide }} \mathrm{Cm}^{-2}\right]}\end{array}$ & $\begin{array}{l}\Delta M_{20 \mathrm{mAcm}^{-2}} 2 \mathrm{~h} \\
{\left[\mathrm{ng}_{\text {oxide }} \mathrm{cm}^{-2} \text { ] }\right.}\end{array}$ \\
\hline $\mathrm{RuO}_{2}$ & $360 \pm 8$ & $\begin{array}{l}\text { EQCM } \\
\text { ICP-MS }\end{array}$ & $\begin{array}{l}-1464 \pm 13 / \\
-1915 \pm 69\end{array}$ & - & $\begin{array}{l}-1566 \pm 110 / \\
-2624 \pm 346\end{array}$ & - \\
\hline $\mathrm{MnO}_{x}$ & $490 \pm 6$ & $\begin{array}{l}\text { EQCM } \\
\text { ICP-MS }\end{array}$ & $\begin{array}{l}-462 \pm 131 / \\
-332 \pm 108\end{array}$ & $\begin{array}{l}-1128 \pm 229 / \\
-1570 \pm 447\end{array}$ & - & $\begin{array}{l}-735 \pm 93 / \\
-793 \pm 194\end{array}$ \\
\hline
\end{tabular}

[a] For both oxides the measured mass losses are shown with corresponding standard deviation from four independent measurements. The overpotentials listed here are from RDE tests based on two independent measurements. Mass losses from EQCM are calculated from the frequency change using the Sauerbrey equation. urements. Mass losses from EQCM are calculated from the frequency
Values for ICP-MS are corrected to the corresponding dioxide masses.

From these measurements, it is clear that solely examining current or potential changes for a small number of hours is insufficient to establish the long-term performance of an OER catalyst in an electrolyser. On the contrary, the anodic dissolution of a catalyst may actually manifest itself over a short-term measurement as an improvement in current density or decreased overpotential, due to an increased surface area. ${ }^{[34]}$ OER conditions may lead to an increase in the microscopic surface area, a decrease in the catalyst surface area and a structural change to a more stable phase; without prior knowledge, it is not possible to determine which of these processes would predominate. Therefore, we emphasise that explicit analyses of mass changes are needed to quantify the stability of these catalysts.

\section{Conclusions}

In conclusion, we have shown that the stability of catalysts for the oxygen evolution reaction can be assessed by means of short-term tests based on a combination of EQCM and ICPMS. It is clear that it is not possible to even roughly estimate the long-term performance of a catalyst on the basis of shortterm chronopotentiometry or chronoamperometry measurements alone. Benchmarking and standardising research efforts are still at an early stage for this reaction. Nonetheless, when a new catalyst is discovered, rigorous and transparent criteria should be applied to establish whether or not the material is stable. While the end goal should be to test catalysts over the long term in actual devices, the quantification of mass losses using well-defined electrodes combined with EQCM and ICPMS provides a less-time-consuming, albeit meaningful, alternative. Finally, although we have focused on the oxygen evolu- 
tion reaction, the findings of this report are general and could be applied to many other electrochemical reactions, including hydrogen evolution, oxygen reduction and $\mathrm{CO}_{2}$ reduction.

\section{Acknowledgements}

The authors gratefully acknowledge financial support from the Danish Ministry of Science's UNIK initiative, Catalysis for Sustainable Energy. The Center for Individual Nanoparticle Functionality is supported by the Danish National Research Foundation (DNRF54). B.W. thanks Formas (project number 219-2011-959) for financial support.

Keywords: corrosion - electrochemistry - heterogeneous catalysis · thin films $\cdot$ water splitting

[1] J. Greeley, N. M. Markovic, Energy Environ. Sci. 2012, 5, 9246.

[2] A. Marshall, B. Børresen, G. Hagen, M. Tsypkin, R. Tunold, Energy 2007, 32, $431-436$.

[3] M. G. Walter, E. L. Warren, J. R. McKone, S. W. Boettcher, Q. Mi, E. A. Santori, N. S. Lewis, Chem. Rev. 2010, 110, 6446-6473.

[4] C. C. L. McCrory, S. Jung, J. C. Peters, T. F. Jaramillo, J. Am. Chem. Soc 2013, 135, 16977-16987.

[5] S. Trasatti, J. Electroanal. Chem. 1980, 111, 125-131.

[6] R. Smalley, MRS Bull. 2005, 30, 00.

[7] Y. Lee, J. Suntivich, K. May, E. E. Perry, Y. Shao-Horn, J. Phys. Chem. Lett. 2012, 3, 399-404.

[8] P. C. K. Vesborg, T. F. Jaramillo, RSC Adv. 2012, 2, 7933.

[9] J. Suntivich, K. J. May, H. A. Gasteiger, J. B. Goodenough, Y. Shao-Horn, Science 2011, 334, 1383-1385.

[10] A. Grimaud, K. J. May, C. E. Carlton, Y.-L. Lee, M. Risch, W. T. Hong, J. Zhou, Y. Shao-Horn, Nat. Commun. 2013, 4, 2439.

[11] Y. Gorlin, T. F. Jaramillo, J. Am. Chem. Soc. 2010, 132, 13612-13614.

[12] M. Gong, Y. Li, H. Wang, Y. Liang, J. Z. Wu, J. Zhou, J. Wang, T. Regier, F. Wei, H. Dai, J. Am. Chem. Soc. 2013, 135, 8452-8455.

[13] W. Sheng, H. A. Gasteiger, Y. Shao-Horn, J. E. Soc, P. B-b, J. Electrochem. Soc. 2010, 157, B1529.

[14] K. Ayers, L. Dalton, E. Anderson, ECS Trans. 2012, 41, 27-38.

[15] M. Piana, M. Boccia, A. Filpi, E. Flammia, H. A. Miller, M. Orsini, F. Salusti, S. Santiccioli, F. Ciardelli, A. Pucci, J. Power Sources 2010, 195, 58755881.

[16] T. Reier, M. Oezaslan, P. Strasser, ACS Catal. 2012, 2, 1765-1772.

[17] K. Macounová, J. Jirkovský, M. V. Makarova, J. Franc, P. Krtil, J. Solid State Electrochem. 2009, 13, 959-965.

[18] R. Forgie, G. Bugosh, K. C. Neyerlin, Z. Liu, P. Strasser, Electrochem. SolidState Lett. 2010, 13, B36.

[19] M. Vuković, J. Appl. Electrochem. 1987, 17, 737-745.

[20] L. Trotochaud, J. K. Ranney, K. N. Williams, S. W. Boettcher, J. Am. Chem. Soc. 2012, 134, 17253-17261.

[21] L. Trotochaud, S. L. Young, J. K. Ranney, S. W. Boettcher, J. Am. Chem. Soc. 2014, 136, 6744-6753.

[22] R. D. L. Smith, M. S. Prévot, R. D. Fagan, Z. Zhang, P. A. Sedach, M. K. J. Siu, S. Trudel, C. P. Berlinguette, Science 2013, 340, 60-63.

[23] J. Blakemore, H. Gray, J. Winkler, A. Müller, ACS Catal. 2013, 3, $2497-$ 2500.

[24] K. Juodkazis, J. Juodkazytè, R. Vilkauskaitè, B. Šebeka, V. Jasulaitienè, CHEMIJA 2008, 19, $1-6$.

[25] K. Stoerzinger, L. Qiao, M. D. Biegalski, Y. Shao-Horn, J. Phys. Chem. Lett. 2014, 5, 1636-1641.

[26] R. Subbaraman, D. Tripkovic, K.-C. Chang, D. Strmcnik, A. P. Paulikas, P. Hirunsit, M. Chan, J. Greeley, V. Stamenkovic, N. M. Markovic, Nat. Mater. 2012, 11, 550-557.

[27] M. Risch, K. A. Stoerzinger, S. Maruyama, W. T. Hong, I. Takeuchi, Y. ShaoHorn, J. Am. Chem. Soc. 2014, 136, 5229-5232.

[28] A. Ohma, K. Shinohara, A. liyama, T. Yoshida, A. Daimaru, ECS Trans. 2011, 41, 775-784.
[29] A. S. Bandarenka, E. Ventosa, A. Maljusch, J. Masa, W. Schuhmann, Analyst 2014, 139, 1274-1291.

[30] L. Tang, B. Han, K. Persson, C. Friesen, T. He, K. Sieradzki, G. Ceder, J. Am. Chem. Soc. 2009, 132, 596-600.

[31] M. Wakisaka, S. Asizawa, H. Uchida, M. Watanabe, Phys. Chem. Chem. Phys. 2010, 12, 4184-4190.

[32] K. J. J. Mayrhofer, J. C. Meier, S. J. Ashton, G. K. H. Wiberg, F. Kraus, M. Hanzlik, M. Arenz, Electrochem. Commun. 2008, 10, 1144-1147.

[33] F. J. Perez-Alonso, C. F. Elkjær, S. S. Shim, B. L. Abrams, I. E. L. L. Stephens, I. Chorkendorff, J. Power Sources 2011, 196, 6085-6091.

[34] K. J. May, C. E. Carlton, K. A. Stoerzinger, M. Risch, J. Suntivich, Y.-L. Lee, A. Grimaud, Y. Shao-Horn, J. Phys. Chem. Lett. 2012, 3, 3264-3270.

[35] J. C. Meier, I. Katsounaros, C. Galeano, H. J. Bongard, A. A. Topalov, A. Kostka, A. Karschin, F. Schüth, K. J.J. Mayrhofer, Energy Environ. Sci. 2012, 5, 9319.

[36] M. Vuković, J. Chem. Soc. Faraday Trans. 1990, 86, 3743-3746.

[37] N. Danilovic, R. Subbaraman, K.-C. Chang, S. H. Chang, Y. Kang, J. D. Snyder, A. P. Paulikas, D. Strmcnik, Y.-T. Kim, D. J. Myers, V. R. Stamenkovic, N. M. Markovic, J. Phys. Chem. Lett. 2014, 5, 2427-2478.

[38] B. Wickman, H. Grönbeck, P. Hanarp, B. Kasemo, J. Electrochem. Soc. 2010, 157, B592-B598.

[39] S. Cherevko, A. R. Zeradjanin, A. A. Topalov, N. Kulyk, J. J. Mayrhofer, ChemCatChem 2014, DOI: 10.1002/cctc.201.

[40] S. Cherevko, A. a. Topalov, A. R. Zeradjanin, I. Katsounaros, K. J. J. Mayrhofer, RSC Adv. 2013, 3, 16516-16527.

[41] L. Xing, M. A. Hossain, M. Tian, D. Beauchemin, K. T. Adjemian, G. Jerkiewicz, Electrocatalysis 2014, 5, 96-112.

[42] D. A. Buttry, M. D. Ward, Chem. Rev. 1992, 92, 1355-1379.

[43] G. Lodi, E. Sivieri, A. De Battisti, S. Trasatti, J. Appl. Electrochem. 1978, 8, $135-143$.

[44] H. Over, Chem. Rev. 2012, 112, 3356-3426.

[45] E. A. Paoli, F. Masini, R. Frydendal, D. Deiana, C. Schlaup, M. Malizia, T. W. Hansen, S. Horch, I. E. L Stephens, I. Chorkendorff, Chem. Sci. 2014, DOI: 10.1039/C4SC02685C.

[46] H. Dau, C. Limberg, T. Reier, M. Risch, S. Roggan, P. Strasser, ChemCatChem 2010, 2, 724-761.

[47] Y. Gorlin, T. F. Jaramillo, J. Electrochem. Soc. 2012, 159, H782-H786.

[48] K. L. Pickrahn, S. W. Park, Y. Gorlin, H.-B.-R. Lee, T. F. Jaramillo, S. F. Bent, Adv. Energy Mater. 2012, 2, 1269-1277.

[49] K. Mette, A. Bergmann, J.-P. Tessonnier, M. Hävecker, L. Yao, T. Ressler, R. Schlögl, P. Strasser, M. Behrens, ChemCatChem 2012, 4, 851-862.

[50] J. W. Desmond Ng, Y. Gorlin, T. Hatsukade, T. F. Jaramillo, Adv. Energy Mater. 2013, 3, 1545-1550.

[51] D. M. Robinson, Y. B. Go, M. Mui, G. Gardner, Z. Zhang, D. Mastrogiovanni, E. Garfunkel, J. Li, M. Greenblatt, G. C. Dismukes, J. Am. Chem. Soc. 2013, 135, 3494-3501.

[52] G. Sauerbrey, Z. Phys. 1959, 155, 206-222.

[53] C. Gabrielli, M. Keddam, R. Torresi, J. Electrochem. Soc. 1991, 138, 2657 2660.

[54] C. Boman, Acta Chem. Scand. 1970, 24, 116-122.

[55] Y. Gorlin, B. Lassalle-Kaiser, J. D. Benck, S. Gul, S. M. Webb, V. K. Yachandra, J. Yano, T. F. Jaramillo, J. Am. Chem. Soc. 2013, 135, 8525-8534.

[56] V. Di Castro, G. Polzonetti, J. Electron Spectrosc. Relat. Phenom. 1989, 48, $117-123$.

[57] H.-Y. Su, Y. Gorlin, I. C. Man, F. Calle-Vallejo, J. K. Nørskov, T. F. Jaramillo, J. Rossmeisl, F. Jaramillo, Phys. Chem. Chem. Phys. 2012, 14, 14010-14022.

[58] R. Kötz, H. J. Lewerenz, S. Stucki, J. Electrochem. Soc. 1983, 130, 825 829.

[59] W. H. Baur, Acta Crystallogr. Sect. B 1976, 32, 2200-2204.

[60] M. Pourbaix, Atlas of Electrochemical Equilibria in Aqueous Solutions, Pergamon Press, Oxford, 1966.

[61] A. Topalov, I. Katsounaros, M. Auinger, S. Cherevko, J. C. Meier, S. O. Klemm, K. J. J. Mayrhofer, Angew. Chem. Int. Ed. 2012, 51, 12613-12615; Angew. Chem. 2012, 124, 12782-12784.

[62] ICP Application Note for iCAP-QC, Thermo Fisher Scientific, 2012.

Received: July 31, 2014

Published online on October 5, 2014 